\title{
Papers
}

\section{Dose-response relation of inhaled fluticasone propionate in adolescents and adults with asthma: meta-analysis}

\author{
Shaun Holt, Aneta Suder, Mark Weatherall, Soo Cheng, Philippa Shirtcliffe, Richard Beasley
}

\begin{abstract}
Objective To examine the dose-response relation of inhaled fluticasone propionate in adolescents and adults with asthma.

Design Meta-analysis of placebo controlled, randomised clinical trials that presented data on at least one outcome measure of asthma and that used at least two different doses of fluticasone.

Setting Medline, Embase, and GlaxoWellcome's internal clinical study registers.

Main outcome measures $\mathrm{FEV}_{1}$, morning and evening peak expiratory flow, night awakenings, $\beta$ agonist use, and major exacerbations.

Results Eight studies, with 2324 adolescents and adults with asthma, met the inclusion criteria. Data on doses of $>500 \mu \mathrm{g} /$ day were limited. The dose-response curve for the raw data began to reach a plateau at around 100-200 $\mu \mathrm{g} /$ day and peaked by $500 \mu \mathrm{g} /$ day. A negative exponential model for the data, without meta-analysis, indicated that $80 \%$ of the benefit at $1000 \mu \mathrm{g} /$ day was achieved at doses of $70-170 \mu \mathrm{g} /$ day and $90 \%$ by $100-250 \mu \mathrm{g} /$ day. A quadratic meta-regression showed that the maximum achievable efficacy was obtained by doses of around $500 \mu \mathrm{g} /$ day. The odds ratio for patients remaining in a study at a dose of $200 \mu \mathrm{g}$ /day, compared with higher doses, was 0.73 (95\% confidence interval 0.49 to 1.08 ). Comparison of the standardised difference in $\mathrm{FEV}_{1}$ for an inhaled dose of $200 \mu \mathrm{g} /$ day against higher doses showed a difference in $\mathrm{FEV}_{1}$ of 0.13 of a standard deviation ( -0.02 to 0.29$)$.

Conclusions In adolescent and adult patients with asthma, most of the therapeutic benefit of inhaled fluticasone is achieved with a total daily dose of $100-250 \mu \mathrm{g}$, and the maximum effect is achieved with a dose of around $500 \mu \mathrm{g} /$ day. However, these findings were limited by the lack of data on individual patients and by the paucity of dose-response studies that included doses of $>500 \mu \mathrm{g} /$ day.
\end{abstract}

\section{Introduction}

Inhaled corticosteroids are the most effective antiinflammatory drugs for treating asthma and are recommended for most adult patients with symptomatic chronic asthma. ${ }^{12}$ Since the introduction of the inhaled corticosteroid beclometasone dipropionate in the early 1960s, doses prescribed to patients with asthma have progressively increased. This is shown in the latest version of the British Thoracic Society's guidelines, in which steps 3 to 5 recommend that adults with chronic asthma should take beclometasone and budesonide in doses of $800-2000 \mu \mathrm{g} /$ day in a large volume spacer. ${ }^{1}$ Because of its greater potency, fluticasone propionate is recommended in doses of $400-1000 \mu \mathrm{g} /$ day. The British National Formulary gives a dose range for fluticasone of $200-2000 \mu \mathrm{g} /$ day for adults. ${ }^{3}$ These recommendations are largely pragmatic and were not based on strong scientific evidence of a clinically important dose-response relation in terms of efficacy at these higher doses (in contrast to a relation in terms of adverse systemic effects). ${ }^{4}$

Extensive clinical research on fluticasone before its introduction enabled the dose-response relation of inhaled corticosteroids to be formally examined with confidence..$^{5-12}$ Randomised, placebo controlled, doseresponse studies of fluticasone, primarily in patients with moderate or severe asthma, have studied different outcome measures, including objective measures, such as forced expiratory volume in one second and peak expiratory flow; symptom control, as reflected in $\beta$ agonist use and nocturnal awakening; and, importantly, the exacerbation rate, which has been proposed as the measure of asthma severity requiring the highest dose of inhaled corticosteroid. ${ }^{13}$

We undertook a meta-analysis of the dose-response relation of the inhaled corticosteroid fluticasone in terms of efficacy in adolescents and adults with asthma. We discuss our findings in relation to different outcome measures, the systemic adverse effects, consistency with recent studies of the dose-response relation of other inhaled corticosteroids, the importance of the results for clinicians, and the implications for national and international guidelines and formularies that make recommendations on the treatment of asthma.

\section{Methods \\ Search strategy}

To identify all studies that investigated the doseresponse relations of fluticasone in terms of efficacy we conducted a search of Medline from January 11966 to December 1999 and of Embase from 1980 to December 1999. On Medline we combined a search of studies containing the keyword "fluticasone" with a search using the MeSH subject heading "asthma" and "chemi-
Wellington Asthma
Research Group,
Wellington School
of Medicine, PO
Box 7343,
Wellington, New
Zealand
Shaun Holt
research fellow
Aneta Suder
medical student
Mark Weatherall
senior lecturer
Soo Cheng
biostatistician
Philippa Shirtcliffe
research fellow
Richard Beasley
professor of medicine
Correspondence to:
R Beasley
beasley@wnmeds.
ac.nz
BMj2001;323:1-8 


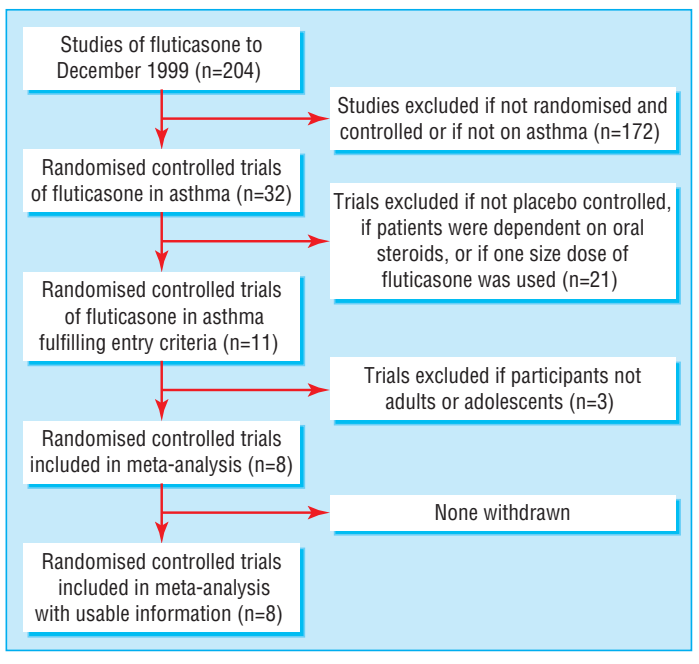

Fig 1 Process of inclusion of studies in the meta-analysis

cal and pharmacologic phenomena" (MeSH) or "doseresponse relationship, drug" (MeSH) or the keywords "dose" or "dosage." When limited to English language only, this search produced 158 papers. On Embase we searched for studies containing the keywords "fluticasone" and "dose" or "dosage." When limited to English, the search produced 159 papers. Many of these studies were also in the Medline search; the total number of different studies was 204.

We also asked GlaxoWellcome, the manufacturer of fluticasone, for details of all relevant studies. No additional studies were identified, including studies not published in English. We did not find any relevant studies published in other languages on Medline or Embase. Finally, we examined the reference lists of relevant studies but found no other studies.

\section{Inclusion criteria}

Two people examined each paper's title and abstract, and then the full paper if necessary. To be included in this meta-analysis, studies had to meet all the following criteria: a double blind, randomised, placebo controlled trial of adolescents ( $\geqslant 12$ years of age) or adults with asthma; more than one dose of inhaled fluticasone was studied; fluticasone was delivered by one device; and data on measures of clinical efficacy were reported. Studies in which participants were dependent on oral steroids or involved in oral steroid reduction regimes were excluded. The search strategy, as recommended by the QUORUM statement, is shown in figure 1 .

\section{Data extraction}

Extraction of data was based on reported summary statistics (means, standard deviations, standard errors of means) for the intention to treat population. The outcome measures assessed were forced expiratory volume in one second $\left(\mathrm{FEV}_{1}\right)$, measured at the clinic, peak expiratory flow (both morning and evening), use of $\beta$ agonists, night awakening, and exacerbation or withdrawal rate (in all the studies patients withdrew if they experienced a major exacerbation). Several other outcome measures were used in some studies-for example, quality of life questionnaires and symptom scores-but were not analysed as they were either assessed in only a few studies or assessed using non-comparable methods-for example, different types of symptom score.

\section{Data analysis}

For each outcome measure the mean change reported in each study was plotted against the total daily dose of fluticasone. As the log transformed dose-response relation for inhaled corticosteroids would be expected to be a straight line, the dose-response relation would be expected to fit a negative exponential model. For this reason we modelled a negative exponential curve of the mean relative percentage change from baseline for each outcome measure, weighted by the number of participants in the study. From this graph the doses at which $80 \%$ and $90 \%$ of the effect obtained with 1000 $\mu \mathrm{g} /$ day were determined. The effect obtained with $1000 \mu \mathrm{g} /$ day of fluticasone was considered to be the "maximum effect" for the purposes of this analysis. We were unable to estimate the confidence intervals of the outcome measures of this model from the published data.

We used meta-regression to compare the effect of change in dose of fluticasone on the asthma response variables. A general linear model weighted by the inverse of the calculated variance for each variable was used. ${ }^{14}{ }^{15}$ Scatter plots of the response and explanatory variable (the total daily dose of inhaled fluticasone) suggested a curved relation, so for this measure we used a quadratic model. Another reason for using this model is that it would not have been possible to calculate the peak dose from the negative exponential model. The variance for each response variable was calculated from the standard deviation or standard error cited in each paper by using the initial number of randomised patients for each treatment category. The standard error of one of the studies was estimated from the size of the error bars on a graph of the response variable. $^{7}$ Analysis of residuals indicated that normality and other assumptions were met. The peak dose effect for the quadratic model was calculated by $\beta_{1} /\left(2 \times \beta_{2}\right)$, where $\beta_{1}$ was the parameter for the dose of fluticasone and $\beta_{2}$ was the parameter for the square of the dose. The weighted model variance was used to calculate $95 \%$ confidence intervals for the predicted response at this predicted peak dose. We used the Bonferroni adjustment to adjust for multiple tests. Both a fixed effects and random effects model were used.

We pooled the odds ratios, using both a fixed and random effects model, according to whether patients taking a dose of fluticasone of $200 \mu \mathrm{g}$ /day remained in a particular study, compared with patients taking higher doses.

We also undertook a meta-analysis of the difference in effect on $\mathrm{FEV}_{1}$ of an inhaled dose of $200 \mu \mathrm{g}$ /day of fluticasone, compared with higher doses, based on the standardised difference in $\mathrm{FEV}_{1}$ for the four studies from which data could be extracted. ${ }^{16}$ Both a fixed and random effects model were fitted.

Reasons for withdrawal varied considerably among studies. Analysis of the numbers of patients that withdrew from the placebo arm of each paper because of clinical deterioration, which could include failure to meet predetermined criteria as well as any clinical exacerbation, was carried out using a general linear mixed model. The pooled proportion of withdrawn patients (in studies that stated reasons for withdrawal) 
Table 1 Summary of studies included in meta-analysis of trials of fluticasone in adults and adolescents with asthma

\begin{tabular}{|c|c|c|c|c|c|c|c|c|c|c|c|c|c|}
\hline \multirow[b]{2}{*}{ Study } & \multirow[b]{2}{*}{$\begin{array}{c}\text { No of } \\
\text { patients }\end{array}$} & \multirow[b]{2}{*}{$\begin{array}{l}\text { Duration } \\
\text { of study } \\
\text { (weeks) }\end{array}$} & \multirow[b]{2}{*}{$\begin{array}{c}\text { Doses of } \\
\text { FP } \\
(\mu \mathrm{g} / \text { day })\end{array}$} & \multirow[b]{2}{*}{ Device } & \multirow{2}{*}{$\begin{array}{c}\text { Range } \\
\text { (mean) of } \\
\mathrm{FEV}_{1} \text { as \% } \\
\text { of predicted }\end{array}$} & \multirow[b]{2}{*}{$\begin{array}{c}\text { Age } \\
\text { (mean) }\end{array}$} & \multirow[b]{2}{*}{$\begin{array}{l}\text { Baseline } \\
\text { ICS usage }\end{array}$} & \multicolumn{6}{|c|}{ Outcomes measured } \\
\hline & & & & & & & & $\mathrm{FEV}_{1}$ & $\begin{array}{l}\text { Morning } \\
\text { PEF }\end{array}$ & $\begin{array}{l}\text { Evening } \\
\text { PEF }\end{array}$ & $\begin{array}{c}\beta \\
\text { agonist } \\
\text { use }\end{array}$ & Exacerbations & $\begin{array}{c}\text { Night } \\
\text { awakenings }\end{array}$ \\
\hline Chervinsky ${ }^{5}$ & 331 & 8 & $\begin{array}{c}50 ; 200 \\
1000\end{array}$ & MDI & $60-90(72)$ & $\geqslant 18(38)$ & $\begin{array}{c}\text { 8-16 } \\
\text { puffs } \\
\text { BDP/ day }\end{array}$ & $\sqrt{ }$ & $\sqrt{ }$ & $\checkmark$ & $\sqrt{ }$ & - & $\sqrt{ }$ \\
\hline Sheffer $^{6}$ & 307 & 12 & $\begin{array}{c}50 ; 100 \\
200\end{array}$ & MDI & $45-75(63)$ & $\geqslant 12(30)$ & 0 & $\sqrt{ }$ & $\sqrt{ }$ & $\checkmark$ & $\sqrt{ }$ & $\sqrt{ }$ & - \\
\hline Galant $^{7}$ & 353 & 12 & $100 ; 200$ & MDI & $45-75(61)$ & $12-75(30)$ & $\geqslant 0$ & $\sqrt{ }$ & $\sqrt{ }$ & - & $\sqrt{ }$ & $\sqrt{ }$ & $\sqrt{ }$ \\
\hline Wolfe $^{8}$ & 281 & 12 & $\begin{array}{c}200 ; 500 \\
1000\end{array}$ & MDI & (65) & $12-87(34)$ & $>0$ & $\sqrt{ }$ & $\sqrt{ }$ & - & $\sqrt{ }$ & $\sqrt{ }$ & $\sqrt{ }$ \\
\hline Lawrence $^{9}$ & 261 & 6 & $\begin{array}{l}200 \\
1000\end{array}$ & Diskhaler & $50-80(66)$ & $\geqslant 18$ & $>0$ & $\sqrt{ }$ & $\sqrt{ }$ & - & $\sqrt{ }$ & $\sqrt{ }$ & $\sqrt{ }$ \\
\hline Wasserman $^{10}$ & 321 & 12 & $\begin{array}{c}100 ; 200 \\
800\end{array}$ & Diskhaler & $50-80$ & $\geqslant 12$ & $\geqslant 0$ & $\sqrt{ }$ & $\sqrt{ }$ & $\sqrt{ }$ & $\sqrt{ }$ & $\sqrt{ }$ & $\checkmark$ \\
\hline Noonan $^{11}$ & 105 & 8 & $100 ; 200$ & MDI & $60-85(74)$ & $12-57(28)$ & 0 & $\sqrt{ }$ & $\sqrt{ }$ & $\sqrt{ }$ & $\sqrt{ }$ & $\sqrt{ }$ & $\sqrt{ }$ \\
\hline Pearlman ${ }^{12}$ & 342 & 12 & $\begin{array}{c}\text { 100; 200; } \\
800\end{array}$ & Diskhaler & $50-80(67)$ & $12-72(35)$ & $>0$ & $\sqrt{ }$ & $\sqrt{ }$ & $\sqrt{ }$ & $\sqrt{ }$ & $\sqrt{ }$ & $\sqrt{ }$ \\
\hline
\end{tabular}

$\mathrm{FP}=$ fluticasone propionate; $\mathrm{FEV}_{1}=$ forced expiratory volume in one second; ICS=inhaled corticosteroid; $\mathrm{PEF}=$ peak expiratory flow; MDI=metered dose inhaler; $\mathrm{BDP}=$ beclometasone dipropionate.

who withdrew because of clinical deterioration was $94 \%$ (95\% confidence interval $80 \%$ to $98 \%)$.We used SAS version 8 (SAS Institute, Cary, NC) and Minitab version 13.2 (Minitab Inc, State College, PA) for the statistical analyses.

\section{Results}

\section{Description of studies}

Eight studies met the criteria for inclusion in this analysis. ${ }^{5-12}$ These studies were published between 1994 and 1998 and were of 6-12 weeks duration (table 1). A total of 2324 adolescents and adults with asthma were included in the studies, with a mean age (range) of 33 (12-87) years. In most studies the patients had moderate or severe asthma, with a mean $\mathrm{FEV}_{1}$ of $66 \%$ of predicted at enrolment (range $45 \%$ to $90 \%$ ). The doses of fluticasone ranged from 50 to $1000 \mu \mathrm{g}$ /day; all studies included the $200 \mu \mathrm{g}$ /day dose. Five studies used doses of $\geqslant 500 \mu \mathrm{g} /$ day. Fluticasone was administered twice daily in all studies, delivered by metred dose inhaler in five studies and Diskhaler in three. As the metred dose inhaler and Diskhaler result in similar lung deposition and have equivalent efficacy, ${ }^{17}$ all eight studies were included in the study. This was supported by our finding that the dose-response relation for fluticasone was similar for both methods of delivery.

\section{Plots of mean change in outcome measure at different doses}

Plotting the raw data for each outcome measure against dose of fluticasone showed the response beginning to plateau at a dose of $100-200 \mu \mathrm{g} /$ day, with little further improvement at higher doses. Only those data points whose variance was included in the text of the published report were plotted, and these points and their variance were used in the quadratic metaregression.

Determination of the dose at which $80 \%$ and $90 \%$ of the effect obtained with $1000 \mu \mathrm{g} /$ day is achieved From the negative exponential line of best fit derived from the weighted means of the effect at each dose, we calculated that $80 \%$ of the benefit obtained with 1000 $\mu \mathrm{g} /$ day was achieved at doses of $70-170 \mu \mathrm{g} /$ day and
$90 \%$ at doses of $100-250 \mu \mathrm{g} /$ day, depending on the outcome measure (table 2).

Determination of the dose at which the maximum response is achieved

For four of the outcome measures it was possible to determine, by quadratic regression, the dose giving the peak effect and to estimate the mean changes in the outcome measures. The dose of peak effect ranged from 560 to $660 \mu \mathrm{g} /$ day (table 3).

Odds ratio of remaining in trials with a dose of $\mathbf{2 0 0}$ $\mu \mathrm{g} /$ day of fluticasone, compared with higher doses

The odds ratios of patients remaining in a trial at a total dose of inhaled fluticasone of $200 \mu \mathrm{g}$ /day, compared with higher doses, for the five trials that used higher doses, are shown in figure $2 .{ }^{5-1012}$ The pooled odds ratio was 0.73 (0.49 to 1.08$)$. A test for homogeneity was not significant, with a value of 6.93 on four degrees of freedom $(\mathrm{P}<0.14)$. The random effects pooled odds ratio was $0.70(0.38$ to 1.3$)$.

Effect on $\mathrm{FEV}_{1}$ of a dose of $200 \mu \mathrm{g} /$ day of fluticasone, compared with higher doses

The meta-analysis of the standardised difference in $\mathrm{FEV}_{1}$ for the four studies that reported these data and that compared a dose of $200 \mu \mathrm{g} /$ day with higher doses showed a difference in $\mathrm{FEV}_{1}$ of 0.13 of a standard deviation, with a confidence interval that included zero ( -0.02 to 0.29$))^{591012}$ The pooled standard deviations for these four studies ranged from 0.431 to $0.76 \mathrm{l}$. The homogeneity statistic was not significant (figure 3). The

Table 2 Doses of fluticasone ( $\mu \mathrm{g} /$ day) at which $80 \%$ and $90 \%$ of the maximum effect is achieved, as derived from a negative exponential model ${ }^{\star}$

\begin{tabular}{lcc} 
Outcome measure & $\begin{array}{c}\mathbf{8 0} \% \text { of maximum effect } \\
\text { achieved }\end{array}$ & $\begin{array}{c}\mathbf{9 0} \% \text { of maximum effect } \\
\text { achieved }\end{array}$ \\
\hline FEV & 146 & 209 \\
\hline Morning PEF & 172 & 247 \\
\hline Evening PEF & 175 & 251 \\
\hline Use of rescue medication & 71 & 102 \\
\hline Major exacerbations & 108 & 155 \\
\hline Night awakenings & 135 & 193 \\
\hline
\end{tabular}

*The effect obtained with $1000 \mu \mathrm{g} /$ day of fluticasone was considered to be the "maximum effect" for the purposes of this analysis.

$\mathrm{FEV}_{1}=$ forced expiratory volume in one second; $\mathrm{PEF}=$ peak expiratory flow. 
Table 3 Estimates of dose of fluticasone ( $\mu \mathrm{g} /$ day) giving peak effect and effect on mean change in outcome measure

\begin{tabular}{lcccccc} 
& & \multicolumn{2}{c}{ Fixed effects model } & & \multicolumn{2}{c}{ Random effects model } \\
\cline { 3 - 6 } Outcome measure & $\mathbf{R}^{2}$ & $\begin{array}{c}\text { Dose of peak } \\
\text { effect }\end{array}$ & Mean change (95\% Cl) & & $\begin{array}{c}\text { Dose of peak } \\
\text { effect }\end{array}$ & Mean change (95\% $\mathbf{~ I ) ~}$ \\
\hline FEV ${ }_{1}(\mathrm{I})$ & $35 \%$ & 568 & $0.62(0.24$ to 1.00$)$ & 628 & $0.70(0.24$ to 1.17$)$ \\
\hline Morning PEF (I/min) & $48 \%$ & 600 & $44(19.5$ to 68.5$)$ & 633 & $50(14.5$ to 86.1$)$ \\
\hline Evening PEF (I/min) & $49 \%$ & 590 & $52(8.6$ to 95.0$)$ & 657 & $51(12.6$ to 89.7$)$ \\
\hline$\beta$ agonist use (puffs/day) & $35 \%$ & 560 & $-1.98(-3.00$ to -0.93$)$ & & 574 & $-2.36(-4.05$ to -0.66$)$ \\
\hline
\end{tabular}

$\mathrm{FEV}_{1}$ =forced expiratory volume in one second; $\mathrm{PEF}=$ peak expiratory flow.



Fig 2 Odds ratio of remaining in a trial at a dose of $200 \mu \mathrm{g} /$ day of fluticasone, compared with higher doses, in the five trials that compared a dose of $200 \mu \mathrm{g} /$ day with higher doses (higher ratio=favours lower dose)

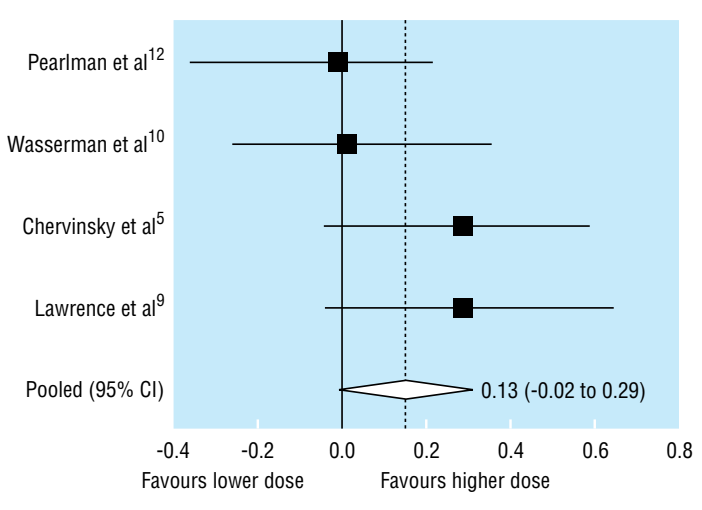

Standardised difference in $\mathrm{FEV}_{1}$

Fig 3 Standardised difference in $\mathrm{FEV}_{1}$ for the four studies that compared $200 \mu \mathrm{g} /$ day fluticasone with higher doses (higher value=favours higher dose)

random effects pooled odds ratio was $0.13(-0.03$ to $0.30)$.

\section{Size of study needed to determine accurately the} dose-response relation

Finally, using data from the meta-analysis, it was possible to determine the approximate size of study needed to test further the hypothesis that higher doses confer significant additional clinical benefit. The weighted mean change in $\mathrm{FEV}_{1}$ at the $200 \mu \mathrm{g} /$ day dose for all studies that used this dose was $0.36 \mathrm{l}$. If an estimate of the standard deviation for the difference between this dose and higher doses is $0.5 \mathrm{l}$, then large studies would be needed to detect a difference in effect of higher doses. For example, with a one sided $\alpha$ of 0.05 , to detect an increase in $\mathrm{FEV}_{1}$ of $20 \%$-that is, a change of $0.07 \mathrm{l}$ for a higher dose-with a power of $80 \%, 630$ patients would need to be randomised into each of two groups. With a power of $90 \%, 875$ patients would be needed in each arm.

\section{Discussion}

We have shown that in adolescents and adults with asthma the dose-response relation of fluticasone for the major outcome measures $\left(\mathrm{FEV}_{1}\right.$, morning and evening peak expiratory flow, night awakenings, $\beta$ agonist use, and major exacerbations) begins to plateau at around 100-200 $\mu \mathrm{g} /$ day, when delivered from a metred dose inhaler or Diskhaler device, and that the maximum achievable benefit occurs by a dose of around $500 \mu \mathrm{g} /$ day. Indeed, most patients with moderate and severe asthma in this analysis had achieved $90 \%$ of the maximum clinical benefit at doses in the range $150-250 \mu \mathrm{g} /$ day, depending on the outcome measure.

\section{Limitations of the study}

A number of issues need to be addressed before the results of this study are considered in detail. The first is whether all available studies were included in the analysis. We are likely to have identified all the eligible trials of fluticasone because of our comprehensive search, thus publication bias is unlikely. Funnel plots (not shown) did not indicate publication bias.

We identified eight studies involving over 2300 patients with asthma, this number providing considerable power to examine the dose-response relation. However, only five of the studies that were eligible for our analysis used doses greater than $500 \mu \mathrm{g} /$ day, and so our results at the higher end of the dose-response relation must be considered with this limitation in mind. As a result, one of our findings is that data in the published literature on which to determine confidently the dose-response relation of fluticasone at doses $>500 \mu \mathrm{g} /$ day are limited. However, the available evidence suggests that further efficacy is not obtained with this higher range.

Another consideration is whether a higher dose of fluticasone would have been required to achieve maximum efficacy if patients with more severe asthma were studied. This possibility was not supported by our study, for the studies were mostly of patients with moderate or severe asthma, whose mean prebronchodilator $\mathrm{FEV}_{1}$ was $66 \%$ of predicted normal values at enrolment despite the fact that most patients used concurrent inhaled corticosteroids.

\section{Key findings}

We used five different methods to analyse the published data, each with its own limitations. It was not possible to undertake more detailed analyses as data 
on individual patients could not be made available to us by GlaxoWellcome.

Firstly, examination of the raw data of the studies indicated that the dose-response curve for all the major clinical outcome measures assessed began to plateau at a dose of between 100 and $200 \mu \mathrm{g} /$ day and peaked at a dose of around $500 \mu \mathrm{g} /$ day.

Secondly, we modelled a negative exponential curve to the mean effect on the six outcome measures, weighted by the number of participants at each dose. This model is likely to be realistic for the effect of inhaled fluticasone, but must be treated with caution, as we were not able to estimate the confidence intervals of the variables of this model by "linearising" the published means and variance data. This model showed that $90 \%$ of the effect achieved at $1000 \mu \mathrm{g} /$ day of inhaled fluticasone was achieved at a dose of $150-250 \mu \mathrm{g} /$ day.

Thirdly, we used a quadratic meta-regression to model the apparent tailing off in efficacy at higher doses of inhaled fluticasone. Although we do not believe that the effect of inhaled fluticasone actually declines at the higher doses, we used this method to estimate a peak effective dose. This method, applied to the four outcome measures for which we were able to derive most data, indicated that a maximum effective dose was around 500-600 $\mu \mathrm{g} /$ day. Although the value of $\mathrm{R}^{2}$ for these models was reasonable, the confidence intervals for each of the parameters of this model were very wide, reflecting the small numbers of studies that had full information on the higher doses of inhaled fluticasone.

Fourthly, we were unable to show evidence of a higher rate of withdrawal in patients taking the lower dose in the five trials that compared $200 \mu \mathrm{g}$ /day of fluticasone with a higher dose. This absence of evidence must be tempered by the small number of withdrawals in some of the studies, which may make the estimate of the pooled odds ratio unstable. ${ }^{59}$ Also, only two studies actually specified whether withdrawals were for worsening asthma or for other reasons, although most withdrawals were for worsening asthma in these two studies. ${ }^{10}{ }^{12}$ The other three studies did not specify that the withdrawals were for worsening asthma. ${ }^{59}$ The $95 \%$ confidence intervals for the point estimate were close to one, so that a small but possibly significant effect of the higher dose on the withdrawal rate may still exist.

Finally, none of the four studies that compared lower doses of inhaled fluticasone with doses of $\geqslant 500$ $\mu \mathrm{g} /$ day, and for which data were available in the published account, was able to show a difference in $\mathrm{FEV}_{1}$ at the higher dose. ${ }^{5910} 12$ The meta-analysis of these data showed that the standardised difference between a dose of $200 \mu \mathrm{g} /$ day and a dose of 500 or $1000 \mu \mathrm{g}$ /day was 0.13 standard deviations, favouring the higher dose, but the $95 \%$ confidence interval for this difference included zero-that is, evidence for a greater effect at a dose higher than $200 \mu \mathrm{g}$ /day is absent.

Thus, all five methods of analysis drew us to the same conclusion: that most of the efficacy of inhaled fluticasone in adult asthma is achieved at a dose of $150-250 \mu \mathrm{g} /$ day and that higher doses conferred minimal further clinical benefit.

\section{Fluticasone compared with other inhaled} corticosteroids

Comparison with the dose-response relation of the inhaled corticosteroids beclometasone dipropionate and budesonide is difficult because of the sparsity of randomised, double blind, placebo controlled doseresponse studies in patients with asthma. Furthermore, the major early studies of both beclometasone and budesonide studied sequentially increasing doses, which made it impossible to differentiate the dose-response relation from the time course relation of efficacy. ${ }^{18}$ More recently, however, a dose-response study of beclometasone administered by metered dose inhaler reported that the top of the dose-response curve in terms of efficacy was $400-800 \mu \mathrm{g} /$ day, depending on the outcome measure. ${ }^{19}$ The findings of a large dose-response study of budesonide delivered by Turbuhaler were similar: no significant differences were noted when doses were doubled from 400 to 800 to $1600 \mu \mathrm{g} /$ day. ${ }^{20}$ If it is assumed that the difference in potency between fluticasone and budesonide or beclometasone is about twofold, the findings of these studies of the dose-response relation of the other inhaled corticosteroids are similar to those of this study examining fluticasone.

In order to strengthen our conclusions at the higher range of the dose-response curve, other studies were identified but were not included in our meta-analysis as they did not meet the selection criteria. One such study found statistically significant but clinically very small differences in clinic assessed $\mathrm{FEV}_{1}$ and peak expiratory flow in adults treated for four weeks with doses of 100, 200,400, and $800 \mu \mathrm{g}$ /day of fluticasone. ${ }^{21}$ Another study, published in abstract form, found no clinically important difference between fluticasone $500 \mu \mathrm{g} /$ day and fluticasone $1000 \mu \mathrm{g} /$ day in terms of effect on morning peak expiratory flow, symptom free days and nights, and exacerbations. ${ }^{22} \mathrm{~A}$ third study found almost no difference between fluticasone $1000 \mu \mathrm{g} /$ day and $2000 \mu \mathrm{g} /$ day in terms of efficacy, but the higher dose produced a highly significant increase in adrenal suppression. ${ }^{23}$ These studies give further evidence that no significant improvement occurs when the dose of fluticasone is increased to $>500 \mu \mathrm{g} /$ day but that significant side effects are more likely.

\section{Cases when higher doses may be warranted}

The findings of this meta-analysis do not exclude the possibility that there may be special circumstances when higher doses are useful. One study has indicated that in cases of severe exacerbations of asthma a high dose of inhaled fluticasone is equivalent in efficacy to oral corticosteroids. ${ }^{24}$ Another such clinical situation is the use of fluticasone in patients dependent on oral steroids; Nelson et al found that $1000 \mu \mathrm{g} /$ day and 2000 $\mu \mathrm{g} /$ day of fluticasone allowed most patients to be weaned off oral corticosteroids. ${ }^{25}$ Thus our findings relate only to the long term, regular treatment of patients with mild, moderate, or severe asthma.

\section{Contrasting dose-response relation of systemic effects}

The dose-response relation in terms of efficacy contrasts with that in terms of systemic effects: there is a linear relation between the dose and the effects on the hypothalamic-pituitary-adrenal axis and bone metabolism, with no evidence of a plateau in response 
for doses up to $2000 \mu \mathrm{g} /$ day. $^{4}$ Consideration of this difference in the dose-response relation between efficacy and adverse systemic effects allows an informal estimate to be made of the risk-benefit ratio for the prescription of different doses of inhaled corticosteroids.

\section{Implications of the findings}

These findings have a number of clinical implications. Firstly, national and international guidelines will need to be modified, such that lower doses of fluticasone are recommended for the treatment of asthma in adolescents and adults. For example, the current guidelines of the British Thoracic Society recommend a dosage of 400-1000 $\mu \mathrm{g} /$ day of fluticasone, administered by a large volume spacer, in steps 3 to 5 to obtain control in the long term management of chronic asthma in adults and schoolchildren. It seems more reasonable to recommend a dosage of 200-500 $\mu \mathrm{g} /$ day in steps 3 and 4 , increasing to $>500 \mu \mathrm{g} /$ day only in step 5 for oral steroid dependent patients.

Secondly, the pragmatic approach that has been recommended of starting inhaled corticosteroids at a high dose, then reducing the dose once the patient's asthma is controlled, should be reconsidered. ${ }^{26}$ The dose-response relation evident in this meta-analysis indicates that this approach may not be required, as also suggested by one major clinical study, which showed that starting with a low dose of budesonide in patients who had not previously used corticosteroids was as effective as the high dose, step down regime. ${ }^{27} \mathrm{In}$ that study, steroid naive patients were prescribed either 200 or $800 \mu \mathrm{g} /$ day of budesonide for 1 month and then $200 \mu \mathrm{g} /$ day for both groups. No significant differences between the two groups were seen, at either 1 month or 3 months.

Thirdly, of the two alternative regimes recommended in the British Thoracic Society guidelines for when asthma is not controlled with fluticasone in a dose of $200-500 \mu \mathrm{g} /$ day, adding a long acting $\beta$ agonist is preferable to increasing fluticasone to a dose of $>500 \mu \mathrm{g} /$ day. This is supported by clinical trials that compared the efficacy of increasing the dose of inhaled corticosteroids with that of adding a long acting $\beta$ agonist. If the dose of inhaled corticosteroid is increased within the observed therapeutic dose range (100-500 $\mu \mathrm{g}$ /day fluticasone or equivalent), such as in the FACET study, then the improvement with the increased dose of inhaled corticosteroid (in terms of reducing severe exacerbations) may be greater than that achieved by the addition of a long acting $\beta$ agonist. ${ }^{28}$ However, if the dose is increased beyond the top of the dose-response curve $(>500 \mu \mathrm{g} /$ day of fluticasone or equivalent), then, not surprisingly, the improvement in asthma control is minimal, and significantly greater benefit is obtained with the addition of the long acting $\beta$ agonist. ${ }^{29-31}$

Fourthly, some of the previous studies that compared the efficacy of different inhaled corticosteroids in patients with asthma will need to be re-examined. Many of these studies compared doses that are at, and in some cases way beyond, the top of the dose-response range, which in the light of our findings is inappropriate. ${ }^{32}$ This consideration assumes even greater importance in studies that compare the new

\section{What is already known on this topic}

Inhaled corticosteroids are recommended for most patients with asthma, with the dose being increased as required to obtain control

A therapeutic dose range of fluticasone propionate of 200-2000 $\mu \mathrm{g} /$ day is recommended in the British National Formulary for adults with asthma

\section{What this study adds}

Published data are insufficient to determine with confidence the dose-response relation of inhaled fluticasone at doses of $>500 \mu \mathrm{g} /$ day

The dose-response curve for inhaled fluticasone in moderate to severe asthma in adolescents and adults, for all major clinical outcome measures, including exacerbations, begins to plateau at $100-200 \mu \mathrm{g} /$ day and peaks at around $500 \mu \mathrm{g} /$ day

This study partially explains why adding a long acting $\beta$ agonist to inhaled corticosteroids is more efficacious than increasing the dose of inhaled steroid beyond this dose range

devices that have been developed to replace metered dose inhalers containing chlorofluorocarbons.

\section{Conclusions}

The dose-response curve for inhaled fluticasone in adolescents and adults with asthma, for all outcome measures, begins to plateau at $100-200 \mu \mathrm{g}$ /day and peaks at around $500 \mu \mathrm{g} /$ day. Despite the limitation of the lack of data for doses of $>500 \mu \mathrm{g} /$ day, national and international guidelines and formularies need to be modified so that they are consistent with the published data from which this therapeutic dose-response relation has been derived. This study partially explains why adding a long acting $\beta$ agonist is more efficacious than increasing the dose of fluticasone beyond a dose of $200-500 \mu \mathrm{g} /$ day (or equivalent for other inhaled corticosteroids). Prescribing inhaled corticosteroids for asthma within this therapeutic dose range, which has been determined from randomised, placebo controlled trials, will provide benefits in terms of efficacy, side effects, and cost.

We are grateful to Julian Crane for his review of the manuscript and Stephanie Easthope for help with data analysis.

Contributors: SH developed the protocol, organised the search, undertook data extraction, and wrote the paper. AS undertook the searches, extracted data, and initiated data analysis. MW and SC were responsible for data analysis and statistical methodology. PS organised the search and contributed to final manuscript preparation. RB was involved in the original concept, oversaw the study, and contributed to the data analysis and final manuscript preparation. SH will act as guarantor for this paper.

Funding: The Wellington Asthma Research Group is supported by grants from the Health Research Council of New Zealand and the New Zealand Guardian Trust.

Competing interests: The Wellington Asthma Research Group has received research grants from Astra Draco, Glaxo Wellcome, and Novartis. RB has received fees for consulting and speaking and reimbursement for attending symposiums from Astra Draco and GlaxoWellcome. SH has received reimbursement for attending symposiums from Astra Draco and Novartis. 
1 British Asthma Guidelines Coordinating Committee. British guidelines on asthma management: 1995 review and position statement. Thora 1997;52(suppl):S1-24.

2 National Heart, Lung, and Blood Institute, National Institutes for Health. Global strategy for asthma management and prevention: NHLBI/WHO workshop report. Bethesda, Maryland: National Institutes of Health, 1996.

3 British Medical Association, Roval Pharmaceutical Society of Great Britain. British national formulary. London: BMA, RPS, 2000:147. (No 40.)

4 Lipworth B. Systemic adverse effects of inhaled corticosteroid therapy. A systematic review and meta-analysis. Arch Intern Med 1999;159:941-55.

5 Chervinsky P, van As A, Bronsky EA, Dockhorn R, Noonan M, LaForce C, et al. Fluticasone propionate aerosol for the treatment of adults with mild to moderate asthma. Fluticasone Propionate Asthma Study Group. JAllergy Clin Immunol 1994;94:676-83.

6 Sheffer AL, LaForce C, Chervinsky P, Pearlman D, Schaberg A Fluticasone propionate aerosol: efficacy in patients with mild to moderate asthma. Fluticasone Propionate Asthma Study Group. J Fam Pract 1996;42:369-75

7 Galant SP, Lawrence M, Meltzer EO, Tomasko M, Baker KA, Kellerman DJ. Fluticasone propionate compared with theophylline for mild-tomoderate asthma. Ann Allergy Asthma Immunol 1996;77:112-8.

8 Wolfe JD, Selner JC, Mendelson LM, Hampel F Jr, Schaberg A. Effectiveness of fluticasone propionate in patients with moderate asthma: a doseranging study. Clin Ther 1996;18:635-46.

9 Lawrence M, Wolfe J, Webb DR, Chervinsky P, Kellerman D, Schaumberg $\mathrm{JP}$, et al. Efficacy of inhaled fluticasone propionate in asthma results from topical and not systemic activity. Am J Respir Crit Care Med 1997;156:744 51.

10 Wasserman SI, Gross GN, Schoenwetter WF, Munk ZM, Kral KM, Schaberg A, et al. A 12-week dose-ranging study of fluticasone propionate powder in the treatment of asthma. J Asthma 1996;33:265-74.

11 Noonan MJ, Chervinsky P, Wolfe J, Liddle R, Kellerman DJ, Crescenzi KL. Dose-related response to inhaled fluticasone propionate in patients with methacholine-induced bronchial hyperresponsiveness: a double-blinc placebo-controlled study. J Asthma 1998;35(2):153-64.

12 Pearlman DS, Noonan MJ, Tashkin DP, Goldstein MF, Hamedani AG, Kellerman DJ, et al. Comparative efficacy and safety of twice daily fluticasone propionate powder versus placebo in the treatment of moderate asthma. Ann Allergy Asthma Immmunol 1997;78:356-62.

13 Barnes PJ, Pederson S, Busse WW. Efficacy and safety of inhaled corticosteroids. New developments. Am J Resp Crit Care Med 1998 157(3 par 2):S1-53

14 Johnson ES, Lanes SF, Wentworth CE, Satterfield MH, Abebe BL, Dicker LA. A meta-regression analysis of the dose-response effect of aspirin on stroke. Arch Intern Med 1999;159:1248-53.

15 Smith SJ, Caudill SP, Steinberg KK, Thacker SB. On combining dose response data from epidemiological studies by meta-analysis. Stat Med $1995 ; 14 \cdot 531-44$

16 D'Agostino RB, Weintraub M. Meta-analysis: a method for synthesizing research. Clin Pharmacol Ther 1995;58:605-16.

17 Lundback B, Alexander M, Day J, Hebert J, Holzer R, Uffelen R van, et al Evaluation of fluticasone propionate $\left(500 \mu \mathrm{g} \mathrm{day}^{-1}\right)$ administered either as dry powder via a Diskhaler inhaler or pressurized inhaler and compared with beclometasone dipropionate $\left(1000 \mu \mathrm{g}\right.$ day $\left.^{-1}\right)$ administered by pressurized inhaler. Respir Med 1993;87:609-20.
18 Toogood JH, Lefcoe NM, Haines DS, Jennings B, Errington N, Baksh L, et al. A graded dose assessment of the efficacy of beclometasone dipropionate aerosol for severe chronic asthma. I Allergy Clin Immuno 1977;59:298-308

19 Busse WW, Brazinsky S, Jacobson K, Stricker W, Schmitt K, Vanden Burgt $\mathrm{J}$, et al. Efficacy response of inhaled beclometasone dipropionate in asthma is proportional to dose and is improved by formulation with a new propellant. J Allergy Clin Immunol 1999;104:1215-22.

20 Busse WW, Chervinsky P, Condemi J, Lumry WR, Petty TL, Rennard S, et al. Budesonide delivered by Turbuhaler is effective in a dose-dependent fashion when used in the treatment of adult patients with chronic asthma. JAllergy Clin Immunol 1998;101:457-63.

21 Dahl R, Lundback B, Malo JL, Mazza JA, Nieminen MM, Saarelainen P, et al. A dose-ranging study of fluticasone propionate in adult patients with moderate asthma. Chest 1993;104(5):1352-58.

22 Ind PW, Dal Negro R, Colman N, Fletcher CP, Browning DC, James MH. Inhaled fluticasone propionate and salmeterol in moderate adult asthma 1; lung function and symptoms. Am J Respir Crit Care Med 1998;157:A416.

23 Ayres JG, Bateman ED, Lunback B, Harris TAJ. High dose fluticasone propionate, $1 \mathrm{mg}$ daily, versus fluticasone propionate, $2 \mathrm{mg}$ daily, or budesonide, $1.6 \mathrm{mg}$ daily in patients with chronic severe asthma. Eur Respir J 1995;8:579-86.

24 Levy ML, Stevenson C, Maslen T. Comparison of short courses of ora prednisolone and fluticasone propionate in the treatment of adults with acute exacerbations of asthma in primary care. Thorax 1996;51:1087-92.

25 Nelson HS, Busse WW, de Boisblanc BP, Berger WE, Noonan MJ, Webb DR, et al. Fluticasone propionate powder: oral corticosteroid-sparing effect and improved lung function and quality of life in patients with severe chronic asthma. J Allergy Clin Immunol 1999;103(2 part 1):267-75.

26 National Asthma Education and Prevention Program (National Heart, Lung, and Blood Institute). Guidelines for the diagnosis and management of asthma: expert panel report 2. Bethseda, MD: National Institutes of Health, 1997.

27 Van der Molen T, Meyboom-de Jong B, Mulder HH, Postma DS. Starting with a higher dose of inhaled corticosteroids in primary care asthma treatment. Am J Respir Crit Care Med 1998;158:121-5.

28 Pauwels RA, Löfdahl C-G, Postma DS, Tattersfield AE, O'Byrne P, Barnes PJ, et al. Effect of inhaled formoterol and budesonide on exacerbations of asthma. N Engl J Med 1997;337:1405-11.

29 Greening AP, Ind PW, Northfield M, Shaw G. Added salmeterol versu higher-dose corticosteroid in asthma patients with symptoms on existing inhaled corticosteroid. Lancet 1994;344:219-24.

30 Woolcock A, Lundback B, Ringdal N, Jacques LA. Comparison of addition of salmeterol to inhaled steroids with doubling of the dose of inhaled steroids. Am J Respir Crit Care Med 1996;153:1481-8.

31 Shrewsbury S, Pyke S, Britton M. Meta-analysis of increased dose of inhaled steroid or addition of salmeterol in symptomatic asthma (MIASMA). BMJ 2000;320:1368-73

32 Barnes NC, Marone G, Di Maria GU, Visser S, Utama I, Payne SL. A comparison of fluticasone propionate, $1 \mathrm{mg}$ daily, with beclometasone dipropionate, $2 \mathrm{mg}$ daily, in the treatment of severe asthma. Eur Respir J $1993 ; 6: 877-84$. 


\title{
Commentary: Dosage needs systematic and critical review
}

\author{
Andrew Herxheimer
}

9 Park Crescent, London N3 2NL

Andrew

Herxheimer

emeritus fellow, $U K$

Cochrane Centre

Andrew

Herxheimer@

compuserve.com
The systematic review by Holt and colleagues is in principle simple and straightforward. They would have been able to do an even more thorough job had they been provided with the data on individual patients from the studies, but their conclusion is convincing and important. With any new drug that has therapeutic activity, an appropriate dosage regimen must be worked out from a clear understanding of the pharmacokinetics and the dose-response relation. When these are known, sensible decisions can be made on the starting dosage, the minimum time to allow before increasing the dose, dose increments, and the maximum useful dose. Why did it take until now, from the first marketing of fluticasone in 1993, to discover that the maximum useful dosage for most cases is only about half of that hitherto recommended by guidelines and the manufacturer? How did the data emerge, and why were they not used earlier?

My guess is that the scientists at GlaxoWellcome (sponsor of the trials in the meta-analysis) and at the Medicines Control Agency and the clinicians and academics working on asthma had not appreciated the need for and value of systematic reviews and appropriate meta-analysis. Also, few systematic reviews have yet examined dose-response relations: these are hardly mentioned in the new edition of Systematic Reviews in Health Care. ${ }^{1}$ Another contributory factor is that clinicians rarely think critically about the doseresponse relations of the drugs they use. Many drugs have been introduced at doses that later were found to be too high; and usually years have passed, with unnecessary toxicity, before action was taken. ${ }^{2}$ This is not acceptable.
As Holt and colleagues hint, it is time to re-examine the dose-response data for beclometasone propionate and budesonide, drugs whose maximum dosages also seem to be about twice what they should be. It is likely that the dose-response relations of other drugs should be revisited. We need to identify the most important of them and begin.

A major obstacle is access to the data. In the case of fluticasone "data on individual patients could not be made available" by GlaxoWellcome. Although Sir Richard Sykes commendably committed the company to openness, there are different degrees of openness. ${ }^{3}$ It would of course have taken time and money to extract the data, and a reanalysis carries the risk of embarrassing findings ${ }^{4}$-but the Medicines Control Agency always has access to the data. Whether it uses them is another question. Because the Medicines Control Agency is wedded to secrecy, we are unlikely to learn the answer. ${ }^{5}$ Making sure that the dosages that are used best serve the patients should be near the top of the agenda for regulators and the prescribing community. Right now this item seems to be nowhere on the agenda-but that needs a separate article.

Competing interests: None declared.

1 Egger M, Davey Smith G, Altman DG, eds. Systematic reviews in health care: meta-analysis in context. London: BMJ Books, 2001. www.systematicreviews.com (accessed 20 May 2001).

2 Herxheimer A. How much drug in the tablet? Lancet 1991;337:346-8.

3 Sykes R. Being a modern pharmaceutical company. BMJ 1998;317:1172.

4 Tramèr MR, Reynolds DJM, Moore RA, McQuay HJ. Impact of covert duplicate publication on meta-analysis: a case study. BMJ 1997:315:63540.

5 Roberts I, Li Wan Po A, Chalmers I. Intellectual property, drug licensing, freedom of information and public health. Lancet 1998;352:726-9. 